\title{
Correction: Cooperation and Discord in South America in the Twenty-First Century
}

Fabio Sanchez

(C) Bahram M. Rajaee and Mark J. Miller, 2012

B.M. Rajaee et al. (eds.), National Security under the Obama Administration,

DOI 10.1057/9781137010476

Correction to:

Chapter 9 in: Fabio Sanchez, Cooperation and Discord in South America in the Twenty-First Century

DOI 10.1057/9781137010476_10

The author Fabio Sanchez Cabarcas in Chapter 9 is incorrect. The author should read as Fabio Sanchez and it has been corrected.

The updated online version of the original chapter can be found at DOI 10.1057/9781137010476_10.

B.M. Rajaee et al. (eds.), National Security under the Obama Administration, DOI 10.1057/9781137010476_14,

(C) Bahram M. Rajaee and Mark J. Miller, 2018 